\title{
AVALIAÇÃO DA EFICIÊNCIA DE SISTEMAS AGROFLORESTAIS POR MEIO DE ANÁLISES FINANCEIRAS
}

\author{
EVALUATION OF EFFICIENCY OF AGROFORESTRY SYSTEMS BY FINANCIAL ANALYSIS
}

\author{
Viviane Helena Palma ${ }^{1}$, Marcelo Francia Arco-Verde², Gustavo Ribas Curcio², \\ Luciano Mansor de Mattos $^{3}$, Martin Ewert ${ }^{4}$, Franklin Galvão ${ }^{1}$ \\ ${ }^{1}$ Universidade Federal do Paraná, Curitiba, Paraná, Brasil - viviane-palma@outlook.com \& \\ fgalvao@ufpr.br
}

Embrapa Florestas, Colombo, Paraná, Brasil-marcelo.arco-verde@embrapa.br \& gustavo.curcio@embrapa.br

${ }^{3}$ Embrapa Cerrados, Brasília, Distrito Federal, Brasil-luciano.mattos@embrapa.br

${ }^{4}$ Universidade Federal de Santa Catarina, Florianópolis, Santa Catarina, Brasil nitram.ewert@gmail.com

\section{RESUMO}

\begin{abstract}
Os Sistemas Agroflorestais (SAFs) têm figurado como alternativa para otimizar o uso das áreas rurais, no sentido de diversificar produção, gerar renda e ainda contribuir com serviços ambientais. Em projetos bem planejados, a diversidade de produtos cultivados em uma mesma área, permite distribuição de mão-de-obra e de produção durante o ano, contribuindo para segurança alimentar e financeira do agricultor, que deixa de depender apenas das flutuações de mercado de um produto. Contudo, ainda não existem respostas contundentes que confirmem a geração de ingressos monetários substanciais de SAFs. Assim, por meio de metodologia participativa aplicada à análise financeira realizada na planilha AmazonSAF 8.1, foram avaliados dois modelos de SAFs. Partindo do pressuposto de que os sistemas analisados deveriam ser produtivos, capazes de passar das fases iniciais e intermediárias, onde os ingressos monetários são dados principalmente por plantas de ciclo curto e semi-perenes, até chegar à fase madura, com receitas advindas das plantas perenes, observa-se que os SAFs-1 e 2 não cumprem as premissas. Problemas advindos desde a incompatibilidade entre propostas dos sistemas, fatores edafoclimáticos e aptidões dos agricultores; escolha de espécies e ausência de manejo; desenho e densidade de plantas contrastantes com os objetivos, foram agentes decisivos no insucesso financeiro temporal dos sistemas.
\end{abstract}

PALAVRAS-CHAVE: Análise temporal, Aptidão do agricultor, Distribuição de mão de obra, Indicadores financeiros, Planejamento.

\section{ABSTRACT}

Agroforestry Systems (AFS) have been an alternative to optimize the use of rural areas, in order to diversify production, generate income and contribute to environmental services. In well-planned projects, the diversity of products grown in the same area allows the distribution of labor and production during the year, contributing to the farmer's food and financial security, which ceases to depend solely on market fluctuations of a product. However, there are no strong answers yet that confirm the generation of substantial AF cash inflows. Thus, through a participatory methodology applied to financial analysis in AmazonSAF 8.1 spreadsheet, were evaluated two models of agroforestry systems. Assuming that the systems analyzed should be productive, capable of passing from the early and intermediate phases, where monetary inflows are mainly given by short-cycle and semi-perennial plants, until reaching the mature phase, with revenues from perennial plants, it is observed that SAFs- 1 and 2 do not fulfill the premises. Problems arising from the incompatibility between the systems proposed, edaphoclimatic factors and skills of farmers; choice of species and lack of management; design and density of plants in contrast with the objectives, were decisive agents in the temporal financial failure of the systems.

KEYWORDS: Temporal analysis, Farmer ability, Labor distribution, Financial indicators, Planning. 


\section{INTRODUÇÃO}

A intensificação da agricultura convencional reduz a resiliência ecológica dos sistemas de uso da terra, enquanto paradoxalmente, as mudanças ambientais e os extremos climáticos exigem uma capacidade de resposta mais alta do que nunca no sentido de tornar os sistemas de uso da terra menos vulneráveis a esses distúrbios (TSCHARNTKE et al., 2011). Em outra frente sabe-se que $78 \%$ das pessoas pobres do mundo (aquelas vivem com até 1,90 dólares por dia), vivem na zona rural, segundo informações do Banco Mundial (2016). No Brasil, apesar de haver um percentual um pouco menor de pessoas residentes no campo que a média mundial, só a agricultura familiar ocupa $67 \%$ do total de mão de obra no setor agropecuário, representa $77 \%$ de seus estabelecimentos, ocupando apenas $23 \%$ da área total dos estabelecimentos rurais (IBGE, 2017).

Nesse sentido, conforme afirmação do Banco Mundial, (2016), a difusão de projetos assertivos, resilientes, produtivos, que possibilitem reforçar os vínculos dos agricultores com os mercados, e que também sejam adequados às pessoas e ao lugares onde serão implantados, são ferramentas cruciais para melhores usos da terra e também no trabalho, para erradicação da pobreza.

Adotar uma visão de longo prazo para lidar com questões de insegurança alimentar e diminuição da pobreza, significa, necessariamente, adotar práticas agrícolas mais sustentáveis e os SAFs são um exemplo destas práticas (FAO, 2015). Percebe-se que em geral, que as iniciativas com SAFs espalhados pelo mundo têm objetivos principais para com a subsistência alimentar, recuperação de áreas e/ou promoção de serviços ambientais, tais como os citados por Luedeling et al. (2011), Vermeulen et al. (2012), Smith \& Mbow (2014), European Commission (2018) e New Zealand Government (2019).

No entanto, a luta efetiva contra a miséria no campo exige desenvolvimento da visão de SAFs produtivos, que já são demanda latente de agricultores que prezam por sistemas que exijam menos mão de obra e agreguem diversidade e eficiência às suas áreas. Sistemas agroflorestais eficazes e eficientes tiram o máximo proveito das interações positivas entre seus vários componentes, para que o produto final seja mais valioso do que na ausência de árvores, enquanto os riscos de falhas nas colheitas e a dependência de insumos químicos são reduzidos (FAO, 2013).

Isto posto, pretendeu-se com esta pesquisa apresentar resultados inerentes à eficiência de modelos de SAFs por meio de análise financeira, suportadas por dados de diagnóstico rural participativo (DRP). Estas ferramentas podem auxiliar no planejamento estratégias de combate à pobreza no campo, uma vez que direcionam a escolha de modelos de SAFs adaptados às pessoas, aos locais e aos objetivos estabelecidos, ao mesmo tempo que pode promover práticas agrícolas produtivas mais conservacionistas. Outro benefício da metodologia é a realização prognoses de projetos sem gastos financeiros de agricultores ou de órgãos financiadores, de mão de obra ou de tempo de estabelecimento de espécies no campo. Para tanto, foram analisados dois modelos agroflorestais de 0,5 hectares (ha) cada, por período de 15 anos.

\section{MATERIAL E MÉTODOS}

\section{Descrição dos locais de pesquisa}

A pesquisa foi desenvolvida no sul do Brasil, estado do Paraná, no município Lapa, região metropolitana da capital do Estado, especificamente, no Assentamento Contestado. Segundo a classificação de Köppen, o clima é temperado e úmido, com amplitude térmica de 12,6 a $20,6^{\circ} \mathrm{C}$, média de $17^{\circ} \mathrm{C}$ (WREGE et al., 2012). Ainda no que tange à temperatura, importante destacar que o município tem média anual de 130 horas de insolação, 246 horas de frio (ou seja, horas com temperatura abaixo de $7,2^{\circ} \mathrm{C}$ ) e sofre aproximadamente 17 geadas/ano (WREGE et al. 2012; IAPAR, 2019). As precipitações somam 1.645 mm/ano e são relativamente bem distribuídas (Figura 1) (WREGE et al. 2012).

Por meio de metodologia participativa, foram analisados dois modelos agroflorestais orgânicos (SAF-1 e SAF-2), ambos de agricultores do Assentamento Contestado, por um período de 15 anos. A metodologia participativa foi constituída por etapas prévias à análise financeira, descritas por Arco-Verde (2018): 1) aproximação entre técnicos e agricultores; 2) levantamento de dados edafoclimáticos e apresentação aos agricultores e da 3) infraestrutura e logística; 4) quantificação mão de obra disponível; 5) entendimento do tipo de mercado disponível; 6) levantamento das espécies presentes nas diferentes fases dos SAFs, seu tempo de permanência, material genético e grupos funcionais; 7) entendimento arranjo e composição temporal do sistema, bem como 8) coleta de coeficientes.

Os SAFs 1 e 2 são frutos de projetos já findados que tiveram o mérito de difundir tais modelos no estado do Paraná, fornecendo insumos e pessoal capacitado a replicar o modelo. Na Tabela 1 são apresentadas as composições SAFs 1 e 2, com discriminação das espécies, 
suas funcionalidades principais no sistema e espaçamento de plantio.

O SAF-1, localizado pelas coordenadas centrais 253' 21" S, 4942'32,23" O, foi implantado em $2012 \mathrm{em}$ 0,5 hectares (ha) e manteve esta configuração até 4 anos de sistema. O solo é o Cambissolo Húmico distrófico típico, de textura franca-argilo-arenosa, com amplitude de declive 7-12\% de declive. A família responsável pelo SAF-1 é constituída por casal com aproximadamente 60 anos, ambos membros muito ativos em diversas frentes de ação do Assentamento, o que diminui sobremaneira o tempo disponível para trabalharem no SAF. O casal, apesar de trabalhar há décadas com agricultura, não tinha experiência com sistemas agroflorestais. A composições inicial e madura do sistema segue nas Figuras 1 e 2, onde os retângulos representam os canteiros de plantio e nas imagens há representações das visões superiores e frontais do sistema.

Tabela 1. Espécies, função principal e espaçamentos em cada SAF.

\begin{tabular}{|c|c|c|c|c|}
\hline Nomes científicos & Nomes populares & \multirow{2}{*}{ Principal função } & SAF-1 & SAF-2 \\
\hline \multicolumn{2}{|l|}{ Plantas de ciclo curto e semi-perenes } & & \multicolumn{2}{|c|}{ Espaçamento (m) } \\
\hline Curcuma longa $\mathrm{L}$. & Açafrão & Venda & - & $0,2 \times 0,4$ \\
\hline Lactuca sativa $\mathrm{L}$. & Alface & Venda & $0,3 \times 0,25$ & $0,3 \times 0,25$ \\
\hline Cichorium intybus L. & Almeirão & Venda & $0,2 \times 0,3$ & $0,2 \times 0,3$ \\
\hline Musa spp. & Banana & Adubadora & $6 \times 6$ & $6 \times 6$ \\
\hline Ipomoea batatas (L.) Lam. L. & Batata doce & Venda & $0,25 \times 0,8$ & $0,25 \times 0,8$ \\
\hline Arracacia xanthorrhiza Bancr. & Batata salsa & Venda & - & $0,5 \times 1$ \\
\hline Beta vulgaris $\mathrm{L}$. & Beterraba & Venda & - & $0,1 \times 0,25$ \\
\hline Brassica oleracea var. italica Plenck & Brócolis & Venda & $0,5 \times 0,8$ & $0,5 \times 0,8$ \\
\hline Megathyrsus maximus (Jacq.) B.K. Simon \& S.W.L. Jacobs & Capim mombaça & Adubadora & $7,14 \mathrm{~kg} / \mathrm{ha}$ & - \\
\hline Allium cepa $\mathrm{L}$. & Cebola & Venda & $0,015 \times 0,5$ & - \\
\hline Allium schoenoprasum L. & Cebolinha & Venda & & $0,05 \times 0,05$ \\
\hline Daucus carota L. & Cenoura & Venda & $0,07 \times 0,2$ & $0,07 \times 0,2$ \\
\hline Brassica oleracea var. acephala DC. & Couve & Venda & $0,5 \times 1$ & $0,5 \times 1$ \\
\hline Brassica oleracea var. botrytis $L$. & Couve-flor & Venda & - & $0,4 \times 0,8$ \\
\hline Pisum sativum $\mathrm{L}$. & Ervilha & Seg. alimentar & 16 sementes/m linear & - \\
\hline Cichorium endivia $\mathrm{L}$. & Escarola & Venda & - & $0,4 \times 0,3$ \\
\hline Phaseolus vulgaris $\mathrm{L}$. & Feijão preto & Seg. alimentar & 10 sementes $/ \mathrm{m}$ linear & - \\
\hline Mentha spicata $\mathrm{L}$. & Hortelã & Venda & - & $0,4 \times 0,2$ \\
\hline Colocasia esculenta (L.) Schott & Inhame & Venda & $1,2 \times 0,3$ & $1,2 \times 0,3$ \\
\hline Manihot esculenta Crantz & Mandioca & Seg. alimentar & $1 \times 1$ & - \\
\hline Ocimum basilicum var. pilosum & Manjericão & Venda & - & $0,4 \times 0,6$ \\
\hline Zea mays subsp. mexicana (Schrad.) Iltis & Milho & Seg. alimentar & $0,5 \times 01$ & - \\
\hline Cucumis sativus L. & Pepino & Venda & - & $1,5 \times 1$ \\
\hline Brassica oleracea var. capitata L. & Repolho & Venda & $0,5 \times 0,8$ & $0,5 \times 0,8$ \\
\hline Eruca sativa Mill. & Rúcula & Venda & - & $0,2 \times 0,1$ \\
\hline \multirow[t]{2}{*}{ Petroselinum crispum (Mill.) Fuss } & Salsinha & Venda & - & $0,1 \times 0,2$ \\
\hline & \multicolumn{2}{|l|}{ Plantas perenes } & & \\
\hline Anadenanthera spp. & Angico & Venda & - & $5 \times 6$ \\
\hline Psidium cattleyanum Sabine & Araçá & Venda & - & $10 \times 6$ \\
\hline Citrus spp. & Citros & Venda & $5 \times 6$ & $5 \times 6$ \\
\hline Eucalyptus spp. & Eucalipto & Venda & $3 \times 6$ & - \\
\hline Ficus carica L. & Figo & Venda & $3 \times 6$ & - \\
\hline Acca sellowiana (O. Berg) Burret & Goiaba serrana & Venda & - & 20 unid. \\
\hline Plinia cauliflora (DC.) Kausel & Jabuticaba & Venda & - & 4 unid. \\
\hline Actinidia deliciosa (A. Chev.) C.F. Liang \& A.R. Ferguson & Kiwi & Venda & - & 8 unid. \\
\hline Malus domestica (Suckow) Borkh. & Maçã & Venda & $3 \times 6$ & - \\
\hline Cydonia oblonga Mill. & Marmelo & Venda & $3 \times 6$ & - \\
\hline Pyrus communis L. & Pera & Venda & $3 \times 6$ & - \\
\hline Prunus persica (L.) Batsch & Pêssego & Venda & $3 \times 6$ & - \\
\hline Eugenia uniflora $\mathrm{L}$. & Pitanga & Venda & - & $10 \times 6$ \\
\hline Punica granatum $\mathrm{L}$. & Romã & Venda & - & 8 unid. \\
\hline
\end{tabular}




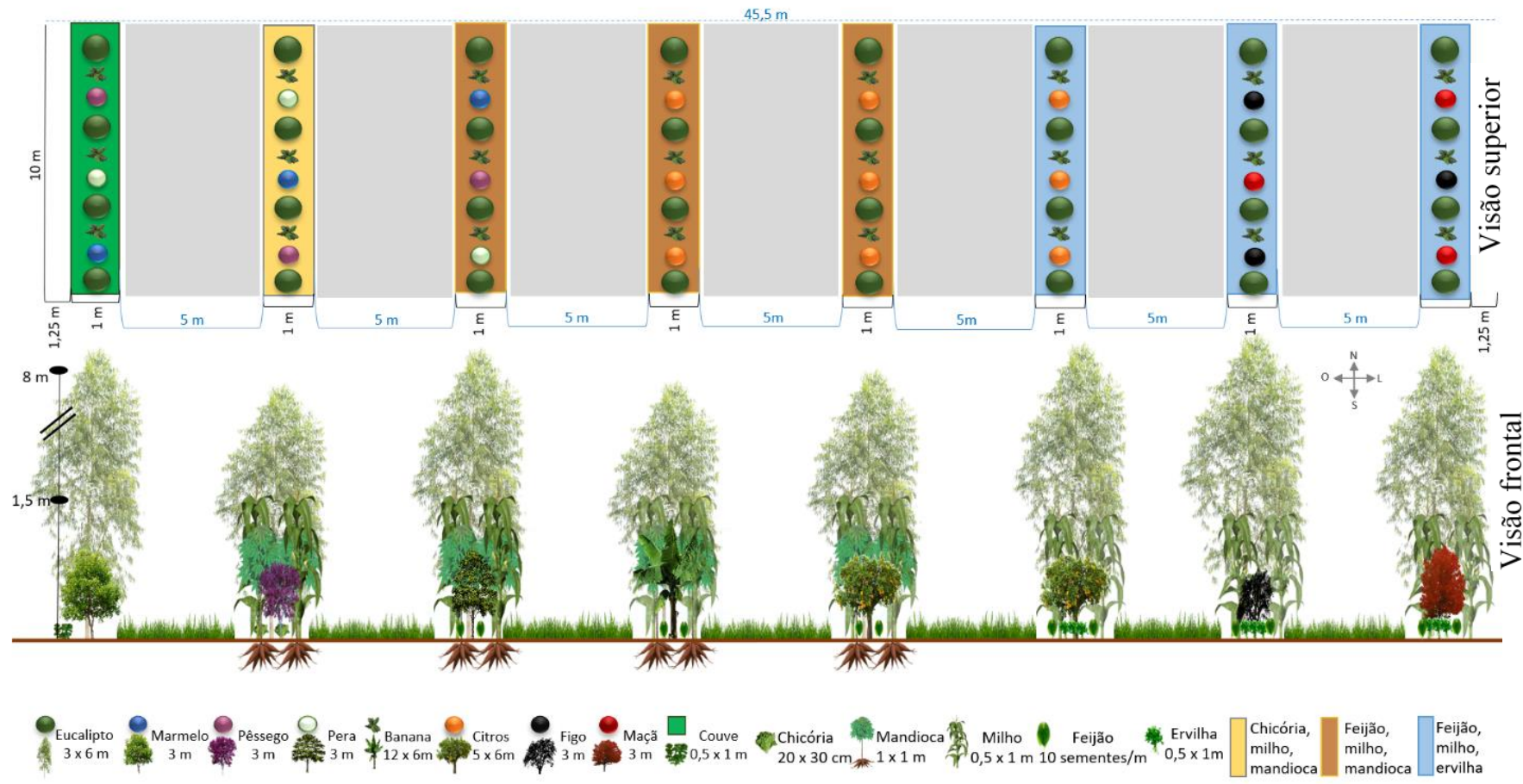

Figura 1. SAF-1. Representação das visões superior e frontal da fase inicial (1 a 4 anos), onde os retângulos representam os canteiros de plantio.

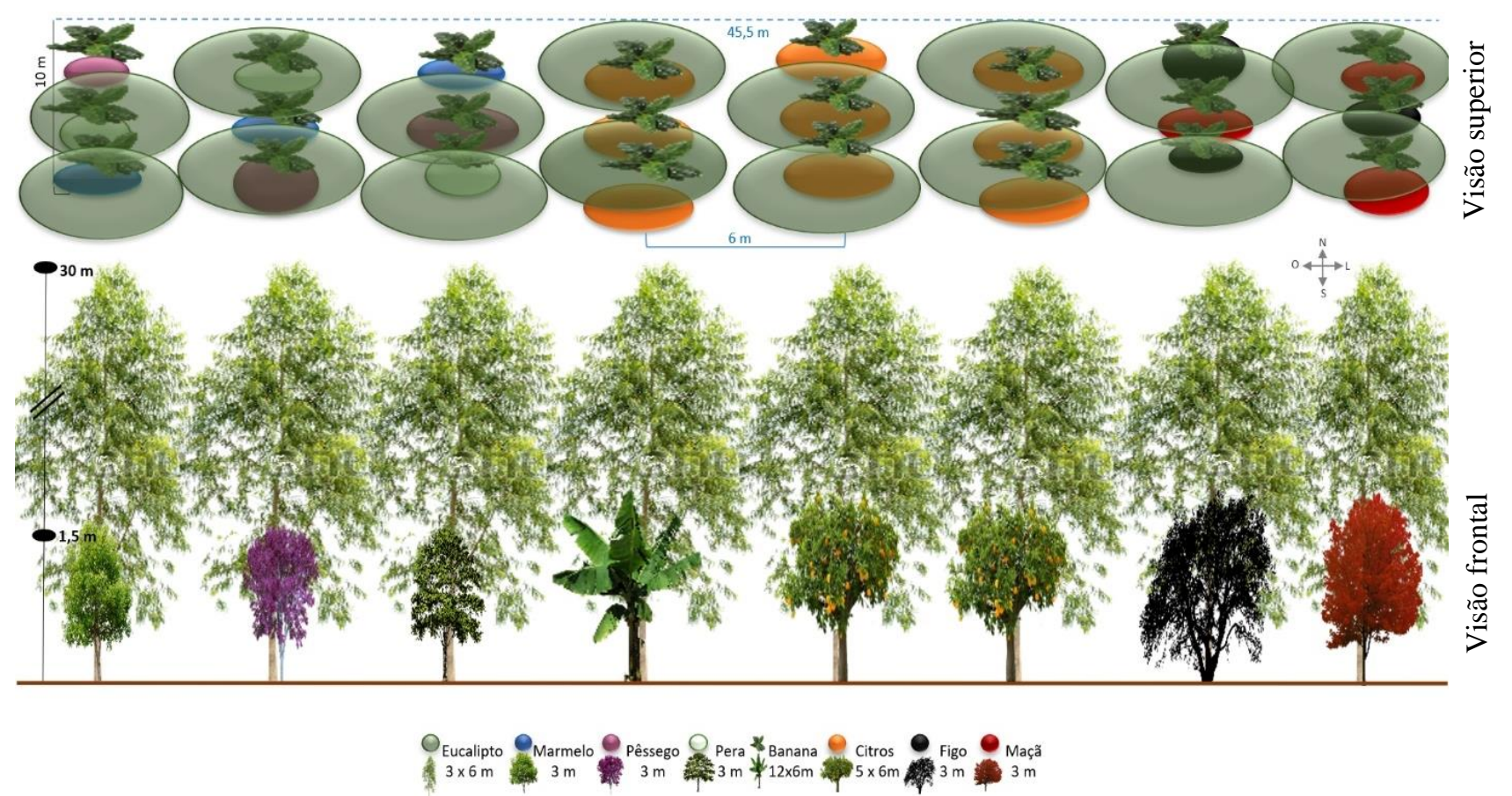

Figura 2. SAF-1. Representação das visões superior e frontal da fase madura (8 a 15 anos).

O SAF-2 foi implantado em área que possui as coordenadas geográficas centrais 4538'25,17" S e 4941'49,64" O, cuja análise também foi realizada para 0,5 ha. Este sistema foi implantado em 2014, sobre dois tipos de solos, de modo que o terço inferior está sobre Gleissolo Melânico Tb distrófico típico, com textura argilo-arenosa e o restante do sistema está sobre Cambissolo Húmico Tb distrófico típico, cuja textura é franca-argilo-arenosa, com amplitude de declividade de 5-13\%. A família responsável pelo SAF-2 é constituída por casal com aproximadamente 43 anos e casal de filhos de 18 e 15 anos. Nenhum membro da família se dedica inteiramente aos cuidados do sistema, pois se dividem entre atividades do Assentamento, de casa e aos estudos. Além disso, a família apenas tinha experiência com cultivos agrícolas solteiros. A composição inicial e madura segue nas Figuras 3 e 4. 

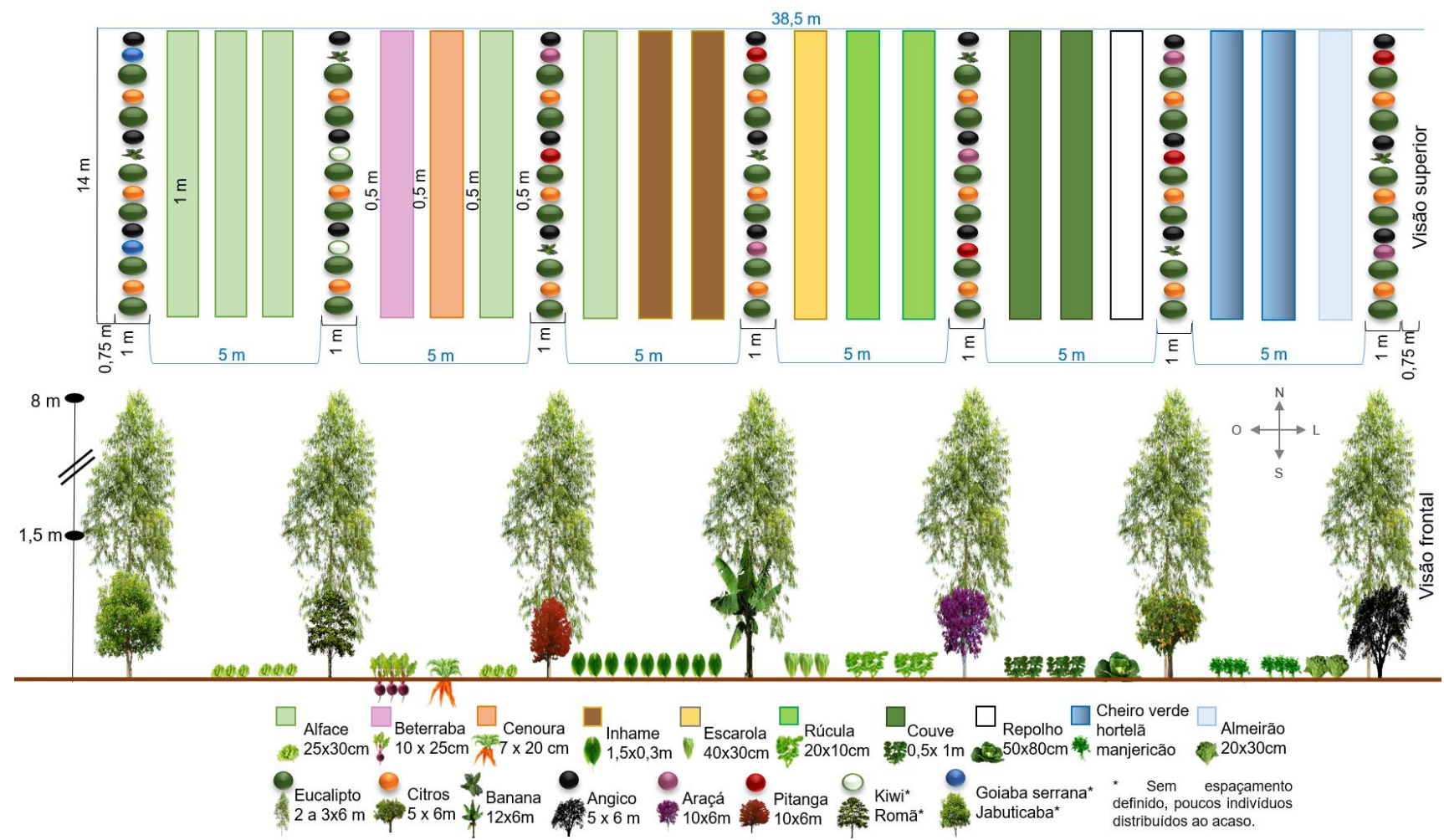

Figura 3. SAF-2. Representação das visões superior e frontal da fase inicial (1 a 4 anos), onde os retângulos representam os canteiros de plantio.

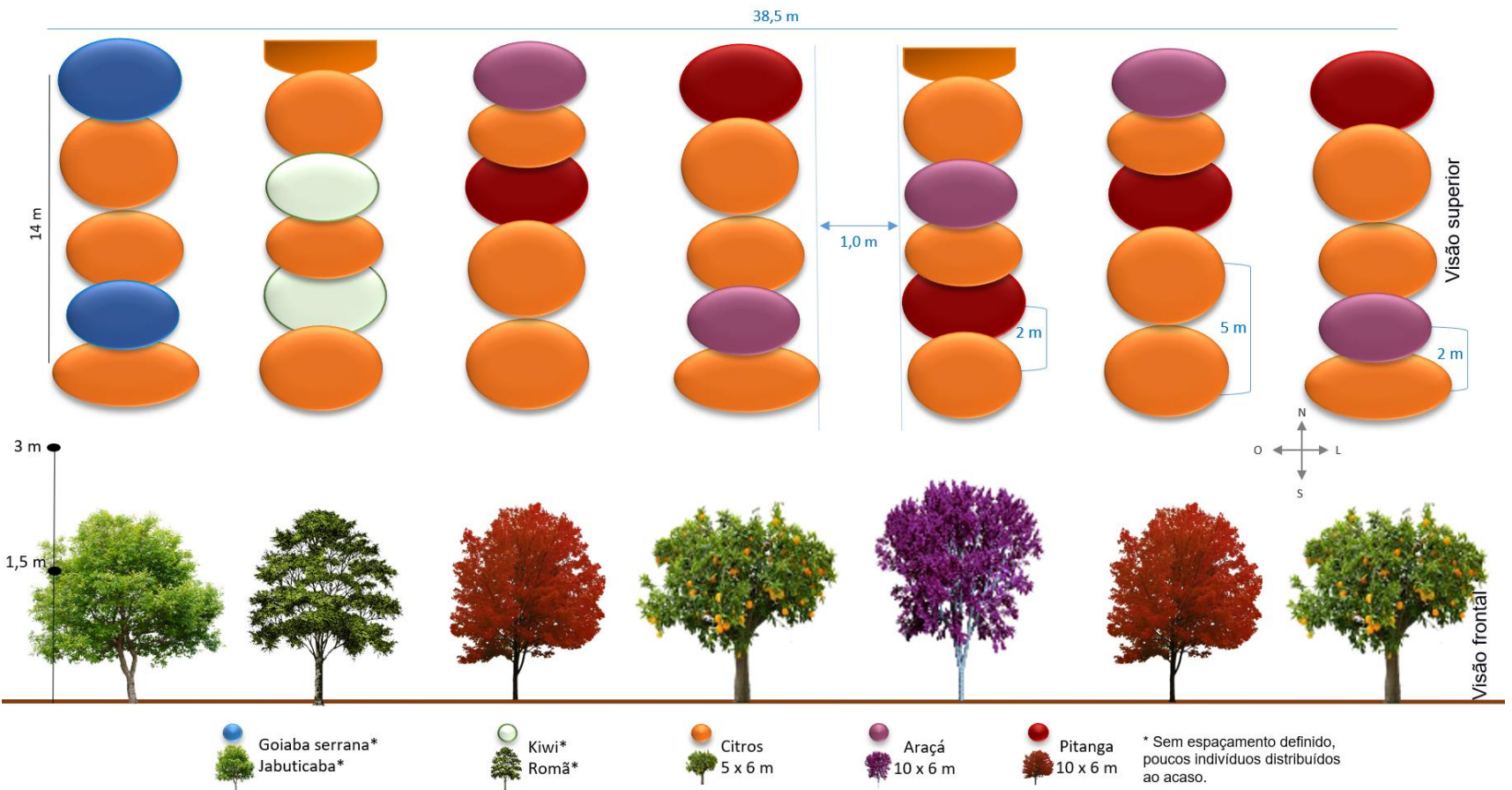

Figura 4. SAF-2. Representação das visões superior e frontal da fase madura (8 a 15 anos).

\section{Método de coleta dos dados}

- Diagnóstico rural participativo (DRP): buscou-se por meio de questionários semiestruturados e de diversas visitas à famílias e aos SAFs, superar limites das intervenções formais, de modo que as famílias estivessem presentes desde os atos de problematização da pesquisa até os de decisão (COELHO, 2014). Estas famílias foram escolhidas devido à experiência com os sistemas e particularidades socioeconômicas (estrutura familiar, aptidões e tipo de comercialização).

- Coleta de solos: foram coletados solos para compor 
amostras compostas segundo metodologia de Lemos \& Santos (1996), nas profundidades de 0-20 cm. Estas amostras foram coletadas em três pontos distintos de cada SAF e analisadas pelo Núcleo de Solos e Estudos Biogeoquímicos da Empresa Brasileira de Pesquisa Agropecuária- Embrapa Florestas.

- Coeficientes técnicos: os agricultores e bibliografia técnico-científica foram consultados para o levantamento das atividades necessárias ao cultivo e manejo das espécies presentes nos SAFs em análise. Contudo, no que tange ao tempo necessário para realização de cada atividade, ou seja, a mão de obra necessária, os agricultores foram as fontes primárias de consulta, visto que esta informação está estritamente ligada às questões sociais, culturais, aptidões e maquinário disponível.

- Mercado: os preços dos produtos do SAF-1 são tabelados pelo governo, visto que os agricultores participam do "Programa Nacional de Alimentação Escolar- PNAE", que fornece alimento para escolas estaduais e municipais. No SAF-2 há outro modo de comercialização: a família produz, gerencia, comercializa e entrega cestas semanais diretamente a consumidores de Curitiba. Contudo, salienta-se que os preços praticados não são demasiadamente divergentes, visto que 30\% do valor comercializado do SAF-1 é revertido à Cooperativa que gerencia e transporta os produtos para o PNAE.

\section{Análise dos dados}

Para a análise financeira dos sistemas foi utilizada a planilha AmazonSAF 8.1 desenvolvida e fornecida pela Embrapa (ARCO-VERDE \& AMARO, 2014). Importante salientar que os projetos foram analisados por período igual de 15 anos, área de 0,5 ha e com taxa de juros de 8,1\% ao ano (a.a.).

Para alimentação da planilha e criação dos croquis foram utilizados dados primários e secundários descritos acima. Os coeficientes técnicos determinados para as atividades, os indicadores financeiros gerados pela planilha AmazonSAF 8.1 e croquis criados, foram validados pelos próprios agricultores em reuniões organizadas pelos pesquisadores responsáveis por este trabalho.

Os indicadores financeiros utilizados foram: valor presente líquido (VPL) (Equação (Eq.1), relação benefíciocusto (B/C) (Eq.2), tempo de recuperação do investimento, também conhecido como payback e ainda a taxa interna de retorno modificada (TIRM) (Eq. 3), citados por ArcoVerde; Amaro (2014). Além disso, a planilha possibilita análise de nuances do fluxo de caixa e de demanda de mão de obra por período do projeto, bem como custos e receitas para cada produto do sistema.

$$
\begin{gathered}
V P L=-\mathrm{I}+\sum_{j=1}^{n} \frac{R j-C j}{(1+i)^{j}}=0 \\
B / C=\frac{\sum_{j=0}^{n} R j(1+i)^{j}}{\sum_{j=0}^{n} C j(1+i)^{j}} \\
\sum_{j=0}^{n} \frac{F C S j}{\left(1+k_{d}\right)^{j}}=\frac{\sum_{j=0}^{n} \frac{F C E j\left(1+k_{c}\right)^{n-j}}{C j(1+i)^{j}}}{(1+T I R M)^{n}}
\end{gathered}
$$

Em que: $\mathrm{Rj}=$ receitas no período $\mathrm{j} ; \mathrm{Cj}=$ custos no período $\mathrm{j}$; $\mathrm{i}=$ taxa de desconto (juros); $\mathrm{j}=$ período de ocorrência de $\mathrm{Rj}$ e Cj; $\mathrm{n}$ = duração do projeto, em número de períodos de tempo; $\mathrm{I}$ = investimento inicial; $\mathrm{FCE}$ = fluxo de caixa positivo (entradas); $\mathrm{FCS}=$ fluxo de caixa negativo (saídas); $\mathrm{Kc}=$ taxa de desconto (financiamento) dos fluxos de caixa negativos; $\mathrm{Kd}=$ taxa de capitalização (reinvestimento) dos fluxos de caixa positivos.

Por meio da AmazonSAF 8.1, também pôde ser estimada/calculada a quantidade de alimento possível de ser produzido por cada um dos sistemas ao longo do período de avaliação.

\section{RESULTADOS E DISCUSSÃO}

\section{Solos dos SAFs}

O SAF-1 tem o mesmo tipo de solo em toda sua extensão- Cambissolo Húmico distrófico típico, textura franco-argilo-arenosa. Já o SAF-2 tem dois tipos de solos: no terço inferior há Gleissolo Melânico Tb distrófico típico de textura argilo-arenosa, e nos terços superior e médio (amostras 5 e 6) há Cambissolo Húmico Tb distrófico típico, de textura franco-argilo-arenosa. Todas as amostras foram coletadas na profundidade de $0-20 \mathrm{~cm}$.

Ambas as famílias já exerciam outras atividades na comunidade e nunca haviam traballhado com SAFs, por isso, devido à falta de experiência e acompanhamento técnico em relação às culturas perenes, prevaleceu a aptidão com cultivos agrícolas, sobretudo olerícolas. Salienta-se que apesar da experiência no cultivo das hortaliças, ambos sistemas têm excesso de nutrientes no solo, certificadamente pela falta de orientação técnica que estivesse baseada em análises de solos.

O SAF-1 foi implantado em curvas de nível e o solo sempre esteve coberto. Essas ações conservacionistas seguramente desfavorecem a erosão e a perda acentuada 
de umidade, fatores comuns em solos de textura francaargilo-arenosa. Conforme Saha et al. (2010), os SAFs melhoram as características físicas, químicas e biológicas do solo, mantém a matéria orgânica e auxiliam na disponibilização de minerais de horizontes mais baixos por conta das raízes e ciclagem de nutrientes da serapilheira sobre o solo.

No caso do SAF-2, outro fato a ser considerado é o erro de plotação do sistema na paisagem, que por conseguinte acarreta problemas de ordem produtiva, ambiental e econômica. A começar pelo produtivo, o terço inferior do sistema encontra-se em Gleisssolo, o qual, por apresentar restrições hídricas, sempre apresentará menores taxas de produção que as culturas implantadas sobre o Cambissolo, encontrado no restante da área.

A inclusão de parte do SAF-2 em Gleissolo, área de transição para o Organossolo, também tem agravantes ambientais e monetários, visto que o Gleissolo é zona de descarga hidrológica e, quando saturado por água, favorece remonte erosivo que tem como consequência, a lavagem de nutrientes ou qualquer outra substância inserida no sistema produtivo, tornando-se fonte de contaminação hídrica. Fato que é preponderante no aumento de gastos com insumos (item "Mão de obra e insumos). Estes problemas ainda são agravados pela ausência de curvas de nível, as quais auxiliam na retenção de coloides (matéria orgânica, nutrientes e argila), lembrando que dois terços do sistema estão em solo de textura franca, no qual a perda de argila prejudica muito a estrutura e retenção de nutrientes.

\section{Mão de obra e insumos}

O custo com a mão de obra foi calculado de acordo com os valores pagos no município em questão, sendo $R \$ 60,00$ e $\mathrm{R} \$ 90,00$ por diária e hora máquina, respectivamente. $A$ dinâmica da mão de obra ao longo dos 15 anos de avaliação dos sistemas, segue o fluxo de caixa (Figura 5). No SAF-1, do primeiro ao quarto ano, $77 \%$ da área foi ocupada com capim (Figura 1), quando este foi retirado do sistema e foram inseridos canteiros de hortaliças, a mão de obra demandada ao sistema dobrou. No SAF-2, não houve plantio de capim e toda a área foi utilizada com canteiros de hortaliças e linhas de plantas perenes e semi-perenes (Figura 3), a partir do quinto ano, quando o sistema não comportou mais produção das hortaliças, houve um decréscimo acentuado das diárias dispendidas aos cuidados com o sistema.

$\mathrm{Na}$ implantação dos SAFs não foram considerados fatores socioeconômicos cruciais ao desenvolvimento dos sistemas agroflorestais ao longo dos anos. Segundo Lin (1976); Arco-Verde \& Amaro (2014), entre todas as despesas consideradas nas atividades agrícolas, a mão-de-obra é a mais importante em pequenas propriedades onde a terra e o capital são limitados, e aliado a isso, o nível de treinamento e de qualificação técnica, impactam diretamente na produtividade (BONELLI \& FONTES, 2013; FREITAS \& MACIENTE 2016). Apesar de ter se considerado nestas análises financeiras que a mão de obra familiar foi remunerada, pois representa um custo de oportunidade (MACDICKEN \& VERGARA, 1990; ARCOVERDE \& AMARO, 2015), as famílias de ambos sistemas não tinham disponíveis pessoas suficientes para os cuidados demandados pelas diferentes espécies dos sistemas, visto que também exerciam outras atividades agropecuárias no lote. Desse modo, o número de diárias dispendidas não foi suficiente para manejar a grande variedade de espécies implantadas (Tabela 1).

Outro ponto a se observar é que a demanda constante de trabalho exigido no cultivo das hortaliças e anuais, chegando a 200 diárias por ano em apenas 0,5 ha, é demasiada para agricultores que possuem idades variando de 43 a 60 anos e que não trabalham apenas no SAF. Demanda bastante distinta de SAFs com frutíferas bem manejadas, onde a mão de obra para se manejar 0,5 ha é de aproximadamente 60 diárias/ano nos anos iniciais, chegando a ser de apenas 20 diárias/ano na fase madura (ARCO-VERDE \& AMARO, 2015; ARMENGOT et al., 2016).

A relação entre custos da mão-de-obra e dos insumos de ambos projetos apresenta discrepância. Os custos referentes aos insumos no SAF-2 (R\$ 275.035), é 4,5 vezes superior ao do SAF-1 (R\$60.903), fato explicado pela maior densidade e rotatividade de culturas de ciclo curto somado à diferente estratégia de comercialização, as quais exigem semanalmente gastos com adubos (muitas vezes em excesso) e combustível. Já os custos de mão de obra do SAF-2 (R\$ 78.610) foram apenas 1,6 vezes superiores ao SAF-1 (R\$ 48.644). Portanto, a inexistência de ação técnica exercida de forma correta, fato infelizmente corriqueiro no meio rural, resultou em gastos desnecessários com insumos.

\section{Custos e receitas por produtos e produção de alimentos}

Os cultivos agrícolas de ciclo curto como as hortaliças, geram rendas a partir do primeiro mês de implantação, enquanto os perenes vão se tornando lucrativos ao longo do tempo, e em geral, a partir do 3 o ano de implantação, fazendo com que os agrossilvicultores possam ter que absorver as perdas líquidas iniciais, antes mesmo de se beneficiarem de seus investimentos, reduzindo o 
entusiasmo das pessoas em projetos de longo prazo com culturas perenes (FAO, 2013). A atenção ao manejo das hortaliças e anuais em detrimento das perenes fica evidenciada nos resultados obtidos na planilha AmazonSAF 8.1, os quais demostram que ao longo de 15 anos de análise, apenas elas foram produtivas, ou seja, os SAFs-1 e 2 nunca avançaram com eficiência para além da fase inicial, pois os maiores ingressos monetários do sistemas ocorreram até o sexto ano (Figura 5).

Observando o desenho dos SAFs-1 e 2 (Figuras de 1 a 4), pode-se constatar uma gama de espécies perenes de grande porte plantadas em espaçamentos insuficientes para seu pleno desenvolvimento. Condição que, além de prejudicar a produção de cada indivíduo, aumenta em demasia o sombreamento do sistema, causando competição por luz, água e nutrientes (HARRISON \& HARRISON, 2016). Espécies como Coffea arabica L., Coffea canephora Pierre ex A. Froehner (cafés) e Theobroma cacao L. (cacau), se desenvolvem bem sob nível moderado de sombreamento, visto que são originários de subbosques (Rigal et al., 2020; Tscharntke et al., 2011), diferentemente das espécies perenes abordadas nesta pesquisa (Tabela 1 ).

No desenho do SAF-1 (Figura 1), proposto por agentes externos financiadores e pensado para outras condições edafoclimáticas, pode-se observar que há excessiva densidade de plantas perenes e olerícolas nas linhas de plantio. Somado a isso, as duas espécies plantadas com função principal de adubação- banana e capim (Tabela 1), não foram podadas com a periodicidade necessária, gerando ao longo do tempo, sombreamento, competição por recursos e diminuição da produção. Efeitos do sombreamento na produção de hortaliças e vegetais também foram constatados por Sultana et al. (2018).

Além disso, a presença do capim em $77 \%$ da área do SAF-1, contribuiu para a baixa produtividade nos 4 primeiros anos. O capim possui metabolismo fotossintético C4, o que determina resposta produtiva ao incremento de luz mais eficiente que todas as demais plantas do sistema, as quais possuem metabolismo do tipo C3 (KLUGE et al., 2015). Devido à falta de manejo, os capins afetaram o desenvolvimento das plantas de interesse econômico do sistema. No quinto ano, logo após a retirada do capim do SAF-1, foi disponibilizado maior espaço para produção de hortaliças e plantas anuais, além disso houve morte de muitos pés de bananeira devido às constantes geadas. Fatos que dobraram a mão de obra disponibilizada para o sistema e refletiram no incremento de receitas na ordem de 4,8 vezes em relação ao ano anterior (Figura 5).

A família 2, já ciente das dificuldades em se manejar o capim das entrelinhas e da necessidade de produção de maior volume de hortaliças (maior vocação da família), alterou o desenho proposto por agentes externos financiadores. Neste caso, houve canteiros de hortaliças nas entrelinhas desde o primeiro ano (Figura 3), os quais apresentaram bons retornos financeiros. Contudo, a atenção aos demais componentes do SAF não foi a mesma dada às hortaliças, assim como no SAF-1.

No SAF-2, além da alta densidade de plantas perenes nas linhas, não ocorreu manejo e adubação adequados, ocasionando retardamento do início da produção ou ainda, como para a maioria dos indivíduos, a inexistência de produção. Apesar de também terem sofrido estas consequências, os eucaliptos e angicos, por serem mais rústicas, apresentaram crescimento em altura, o que se deu justamente por estas espécies ocuparem estratos superiores do sistema, onde há oferta de luz. O que corrobora com pesquisa de Salazar-Díaz \& Tixier (2019), que mostra que em estratos mais altos do dossel há complementaridade de benefícios entre plantas, enquanto que a competição é mais forte que a complementaridade para as plantas que ocupam os estratos mais baixos do dossel, com oferta limitada de luz.

Outra observação relevante é a de que mesmo plantadas com o objetivo de produção de madeira, as espécies de eucalipto e angico disponibilizadas aos agricultores não tinham a genética mais indicadas para a finalidade prevista e não incrementaram receitas significativas, visto que estão sendo aproveitadas principalmente como lenha e mourões.

Verificou-se que do ponto de vista técnico, nem todas as combinações de espécies de ciclo curto, anuais, semiperenes e perenes são viáveis, e certas práticas ou espécies arbóreas podem competir excessivamente com as demais espécies (FAO, 2013), prejudicando o desenvolvimento do sistema como um todo. Além disso, eleger espécies ou mesmo variedades inaptas às peculiaridades regionais, é um equívoco ainda comum, assim como o de não se observar elementos socioeconômicos relacionados à quantidade e tipo de mão de obra disponível para manejar o sistema.

Outra informação a se destacar é a da produção de alimentos em cada sistema. Ao longo de um período de 15 anos, o SAF-1 gerou 63 toneladas (ton) de alimentos oriundos de culturas de ciclo curto e anuais e 4,7 ton de alimentos de culturas perenes. Já o SAF-2 produziu 76,7 ton de alimentos de culturas de ciclo curto e 9,4 de frutas oriundas de plantas perenes. Assim o SAF-2, mesmo sem conter na sua composição culturas anuais (milho, feijão e mandioca), produziu aproximadamente $21 \%$ a mais que o 
SAF-1. A maior produção de alimento no SAF-2 foi reflexo principalmente do período inicial do sistema, que teve as entrelinhas ocupadas por canteiros de hortaliças (Figura 3) e não por capim, como aconteceu no SAF-1 (Figura 1).

\section{Análises financeiras}

Os projetos de 0,5 ha foram avaliados por período de 15 anos pela metodologia sugerida por Arco-Verde \& Amaro (2014). A taxa de desconto/juros utilizada é a praticada no "Programa Nacional de Fortalecimento da Agricultura Familiar- PRONAF", já somando o seguro safra, respectivamente 4,6 e $3,5 \%$ ao ano (a.a.). A taxa de reinvestimento considerada foi a estritamente ligada à do PRONAF, sem o percentual referente ao seguro. As taxas utilizadas e os resultados dos indicadores financeiros utilizados podem ser observados na Tabela 2.

Do ponto de vista econômico, observa-se que todos os indicadores financeiros (Tabela 2) apontam viabilidade dos SAFs analisados, pois os VPLs são maiores que zero, payback acontece no máximo no segundo ano, a relação $\mathrm{B} / \mathrm{C}$ é maior que 1 e a TIRM é maior que a taxa de desconto do projeto Arco-Verde \& Amaro (2015). Contudo, o fluxo de caixa (Figura 5) mostra que a partir do ano 9, os custos foram superiores às receitas no SAF-1 e foram diminutos no SAF-2. Ademais, os excessivos gastos com insumos, sobretudo com adubos, não foram bem distribuídos entre os componentes dos SAFs, visto que foram direcionados apenas às hortaliças e anuais. Apesar do excedente nutricional encontrado nos solos atualmente, o direcionamento da fertilidade não foi voltado para o sistema como um todo, praticamente excluindo o componente arbóreo. A necessidade de se compartimentalizar o enfoque nutricional para hortaliças concomitantemente às perenes, todavia ser desse ser preconizado desde a implantação do sistema.

Como há variações significativas nos ingressos e saídas dos SAFs devido às modificações dos sistemas ao longo dos anos, é necessário avaliar de maneira mais profunda as particularidades das diferentes fases de cada projeto. Para tanto, apresenta-se o fluxo de caixa comparativo dos dois projeto Figura 5, onde pode-se observar entradas e saídas monetárias anuais. Os custos de investimento em cada sistema (ano 0), são relativamente baixos, sendo $R \$$ 5.118,00 no SAF-1, R\$7.785,00 e no SAF-2.

Tabela 2. Dados e indicadores financeiros dos projetos.

\begin{tabular}{cccccccc} 
Projeto & Período de avaliação (anos) & Taxa de desconto (\%) & TIRM (\%) & VPL (R\$̦) & Payback descontado (ano) & Relação B/C \\
\hline SAF-1 & 15 & 8,1 & 17,4 & 79580 & 2 & 2,1 \\
SAF-2 & 15 & 8,1 & 21,4 & 213.498 & 1 & 1,8 \\
\hline
\end{tabular}

TIRM= taxa interna de retorno modificada; $\mathrm{VPL}=$ valor presente líquido; $\mathrm{B} / \mathrm{C}=$ benefício-custo.

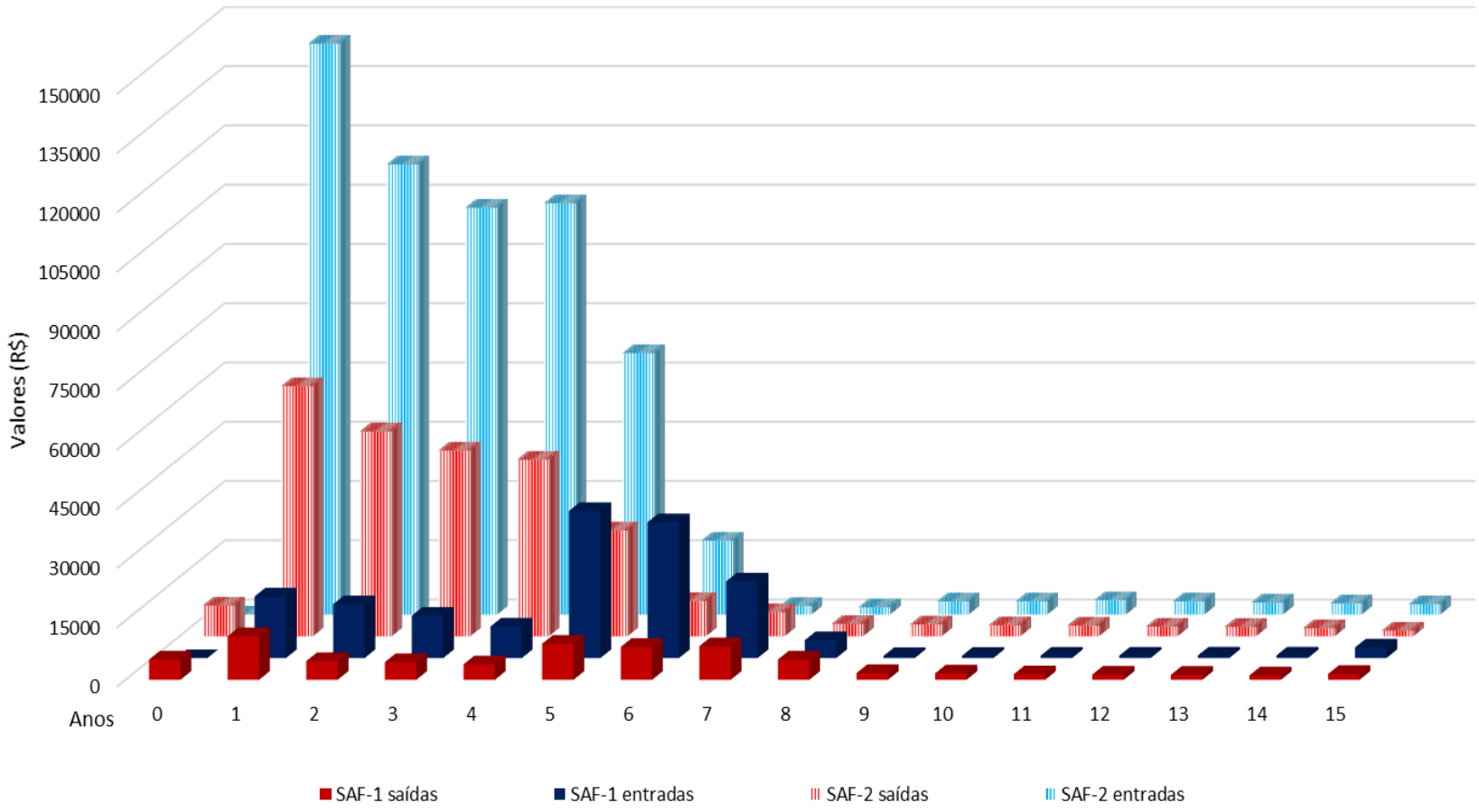

Figura 5. Fluxo de caixa dos SAFs-1 e 2 ao longo de 15 anos. 
Ainda observando os fluxos de caixa (Figura 5), nota-se que o colapso de ambos sistemas se deu justamente na transição de fases (inicial para intermediária), entre o 50 e o 60 ano. Neste ponto, é conveniente lembrar que em sistemas bem manejados desde a implantação, as frutíferas perenes já estariam produzindo, o que mudaria sobremaneira a configuração de ambos fluxos de caixa. Trabalhos de ArcoVerde \& Amaro (2015) e Nunoo \& Owusu (2017), apontam que SAFs com árvores frutíferas/castanhas e madeiráveis têm tendência de se mostrarem mais lucrativos entre as fases intermediária e madura.

Consequentemente, deve-se frisar que a baixíssima produção das frutíferas perenes em ambos sistemas, foi dada à falta de manejo, adubação inicial, alta competição e insegurança quanto à qualidade genética dos indivíduos. O que resultou na estagnação dos SAFs analisados na fase inicial, pois desde o início dos projetos, prevaleceu a aptidão das famílias com hortaliças e a necessidade de se obter renda imediata. Por conseguinte, nos momentos de transição de fases e na ausência de produção de frutíferas, houve abandono dos sistemas. Essa preferência dos agricultores analisados para com as hortaliças em SAFs é distinta da evidenciada em outras regiões do Brasil e do mundo, onde as espécies permanentes, especialmente frutíferas se sobressaem (VIEIRA et al., 2007; HOMBEGOWDA et al., 2019; SALAZAR-DÍAZ \& TIXIER, 2019; STANEK et al., 2019).

Segundo a FAO (2013), a falta de mercados bem desenvolvidos para produtos agroflorestais, combinada com a ênfase nos retornos imediatos observados em alguns projetos agrícolas, e a dificuldade que muitos agricultores enfrentam em investir em atividades com retorno financeiro atrasado, os forçam a descartar a agrofloresta como uma opção viável. Neste caso, por meio do diagnóstico rural participativo, foi identificada alta demanda do mercado regional por frutíferas orgânicas. Entretanto, mesmo assim, a agrofloresta deixou de ser vista como opção viável nos SAFs-1 e 2, entre os anos 5 e 6 (Figura 5), justamente quando os sistemas deixaram de produzir ingressos significativos por não comportarem mais as hortaliças e não produzirem frutos.

Por consequência, a impressão de um projeto de SAF lucrativo ao longo de seus 15 anos, dada pelos indicadores financeiros (Tabela 2), é equivocada e perceptível quando se observa nos fluxos de caixa (Figura 5), o colapso de ambos sistemas a partir do 6o ano, quando o sombreamento das árvores não permitiu a continuidade do cultivo das hortaliças. A inexperiência, falta de assistência e visão a curto prazo, seguramente contribuíram com os colapsos nos SAFs 1 e 2. Verificou-se que apesar dos positivos indicadores financeiros apresentados na Tabela 2, a análise dos fluxos de caixa dos projetos, demonstra que os SAFs 1 e 2 são insustentáveis sem a presença das hortaliças.

Desta maneira, para que futuros projetos de SAFs sejam eficientes na produção de alimentos $e$ financeiramente ao longo de todos os anos, recomenda-se planejamento alinhado com as vocações e disponibilidade de mão de obra dos agricultores, escolha de espécies com bom material genético e adequado às funcionalidades específicas que exercerão no sistema, além de plantio em densidade adequada para atender o mercado. Ademais, o que as análises financeiras apontam é a necessidade de visão a médio e longo prazo, para que os SAFs possam figurar como projetos perenes, onde há ao longo do tempo o aumento da participação de receitas de espécies das fases intermediárias e maduras do sistema, em detrimento daquelas das fases iniciais (hortaliças e anuais, principalmente).

\section{CONCLUSÕES}

Os SAFs-1 e 2 apresentam indicadores financeiros positivos. Entretanto, problemas advindos desde a incompatibilidade entre propostas dos sistemas, fatores edafoclimáticos e aptidões dos agricultores; escolha de espécies e ausência de manejo; desenho e densidade de plantas contrastantes com os objetivos de comercialização, foram elementos decisivos no insucesso financeiro temporal dos sistemas.

\section{AGRADECIMENTOS}

Esta pesquisa foi financiada em parte pela Coordenação de Aperfeiçoamento de Pessoal de Nível Superior - Brasil (CAPES) - Código 001. Além da CAPES, agradecemos à Empresa Brasileira de Pesquisa Agropecuária- EMBRAPA, pelo apoio de infraestrutura e logística necessários à realização deste trabalho. Também registramos profundo agradecimento aos agricultores do Assentamento Contestado pela disponibilidade de tempo e partilha de conhecimento, sem quais este trabalho não teria sido realizado.

\section{REFERÊNCIAS}

ARCO-VERDE, M.F. Análise financeira de sistemas agroflorestais. Curitiba: Embrapa, 2018.

ARCO-VERDE, M.F.; AMARO, G.C. Análise financeira de sistemas produtivos integrados. Colombo: Embrapa Florestas, 2014. Disponivel em: https://www.infoteca.cnptia.embrapa.br/ handle/doc/1014392 
ARCO-VERDE, M.F.; AMARO, G.C. Metodologia para análise da viabilidade financeira e valoração de serviços ambientais em sistemas agroflorestais. Serviços ambientais em sistemas agrícolas e florestais do bioma Mata Atlântica. Brasília: Embrapa, p.335-346, 2015. Disponível em: https://www.alice.cnptia. embrapa.br/alice/bitstream/doc/1024363/1/MarceloAVLivroSer vicosAmbientaisCap30.pdf

ARMENGOT, L. et al. Cacao agroforestry systems have higher return on labor compared to full-sun monocultures. Agronomy for Sustainable Development, v.36, n.4, p.1-10, 2016.

BONELLI, R.; FONTES, J.O desafio brasileiro no longo prazo. Ensaios IBRE de Economia Brasileira - I. Rio de Janeiro: IBRE; FGV, p.249-280, 2013. Disponivel em: https://bibliotecadigital.fgv.br/dspace/bitstream/handle/10438 /11674/Desafios Brasileiros no Longo Prazo - 28_05_2013.pdf

COELHO, F.M.G. A arte das orientações técnicas no campo: concepções e métodos. 2.ed. Viçosa: Suprema, 2014.

EUROPEAN COMMISSION. Agriculture and rural developmentCommon Agriculture Policy (CAP). Disponível em: https://ec.europa.eu/agriculture/direct-support/crosscompliance_en

FAO. Advancing agroforestry on the policy agenda - a guide for decision-makers. Roma: Food and Agriculture Organization of the United Nations, 2013.

FAO. Agroforestry provides practical solutions to global problems, 2015. Disponível em: http://www.fao.org/forestry/ agroforestry /80339/en/

FREITAS, R.E.; MACIENTE, A.N. Requerimentos típicos de mão de obra agrícola. $2016 . \quad$ Disponível em: http://repositorio.ipea.gov.br/handle/11058/6877

HARRISON, S.; HARRISON, R. Modelling approaches for mixed species agroforestry systems. Promoting sustainable agriculture and agroforestry to replace unproductive land use in Fiji and Vanuatu. Camberra: Australian Centre for International Agricultural Research (ACIAR), p.19-37, 2016.

HOMBEGOWDA, H.C. et al. D. Tree species and size influence soil water partitioning in coffee agroforestry. Agroforestry Systems, v.7, p.1-13, 2019.

IAPAR. Dados históricos climáticos de municípios do Paraná 2019.

IBGE. Censo agropecuário 2017. 2017. Disponível em: https://censos.ibge.gov.br/agro/2017/templates/censo_agro/re sultadosagro/index.html

KLUGE, R.A. et al. Aspectos fisiológicos e ambientais da fotossíntese. Revista Virtual de Química, v.7, n.1, p.56-73, 2015.

LEMOS, R.C.; SANTOS, R. Manual de descrição e coleta de solo no campo. 3.ed. Campinas e Rio de Janeiro: Sociedade Brasileira de Ciência do Solo e Embrapa-CNPS, 1996.

LIN, S.A. The modified internal rate of return and investment criterion. The Engineering Economist, v.21, p.237-247, 1976.
LUEDELING, E. et al. Carbon sequestration potential of agroforestry systems in Africa. Carbon Sequestration Potential of Agroforestry Systems in Africa. Dordrecht: Springer, 2011. Disponivel em: http://www.springerlink.com/index/10.1007/ 978-94-007-1630-8_4

MACDICKEN, K.G.; VERGARA, N.T. Agroforestry: classification and management. New York: Wiley, 1990.

BANCO MUNDIAL. Relatório Anual de 2016 do Banco Mundial. Washington, 2016.

NEW ZEALAND GOVERNMENT. One billion trees planting programme. 2019. Disponível em: https://www.teururakau.govt. $\mathrm{nz} /$ funding-and-programmes/forestry/one-billion-treesprogramme/

NUNOO, I.; OWUSU, V. Comparative analysis on financial viability of cocoa agroforestry systems in Ghana. Environment, Development and Sustainability, v.19, n.1, p.83-98, 2017.

RIGAL, C. et al. Coffee production during the transition period from monoculture to agroforestry systems in near optimal growing conditions, in Yunnan Province. Agricultural Systems, v.177, p.1-10, 2020.

SAHA, R. et al. Can agroforestry be a resource conservation tool to maintain soil health in the fragile ecosystem of north-east India? Outlook on Agriculture, v.39, n.3, p.191-196, 2010.

SALAZAR-DÍAZ, R.; TIXIER, P. Effect of plant diversity on income generated by agroforestry systems in Talamanca, Costa Rica. Agroforestry Systems, v.93, n.2, p.571-580, 2019.

SMITH, M.S.; MBOW, C. Editorial overview: Sustainability challenges: Agroforestry from the past into the future. Current Opinion in Environmental Sustainability, v.6, p.134-137, 2014.

STANEK, E.C. et al. Designing multifunctional woody polycultures according to landowner preferences in Central Illinois. Agroforestry Systems, v.93, n.6, p.2293-2311, 2019.

SULTANA, T. et al. Performance of fruit vegetables in summer under mahagony based agroforestry systems. Malaysian Journal of Halal Research (MJHR), v.1, n.2, p.8-14, 2018.

TSCHARNTKE, T. et al. Multifunctional shade-tree management in tropical agroforestry landscapes - a review. Journal of Applied Ecology, v.48, n.3, p.619-629, 2011.

VERMEULEN, S.J. et al. Climate Change and Food Systems. Annual Review of Environment and Resources, v.37, n.1, p.195-222, 2012.

VIEIRA, T.A. et al. Sistemas agroflorestais em áreas de agricultores familiares em Igarapé-Açu, Pará: caracterização florística, implantação e manejo. Acta Amazonica, v.37, n.4, p.549-558, 2007.

WREGE, M.S. et al. Atlas Climático da Região Sul do Brasil. Brasília: Embrapa, 2012.

Recebido em 15-01-2020 Aceito em 19-02-2020 